Supporting Information

\title{
Glycol-Thermal Continuous Flow Synthesis of Graphene Gel
}

\section{Luke C.O. Prestowitz and Jiaxing Huang*}

Department of Materials Science and Engineering, Northwestern University, 2220 Campus Dr., Evanston, IL 60202, USA

*Corresponding author email: jiaxing-huang@northwestern.edu
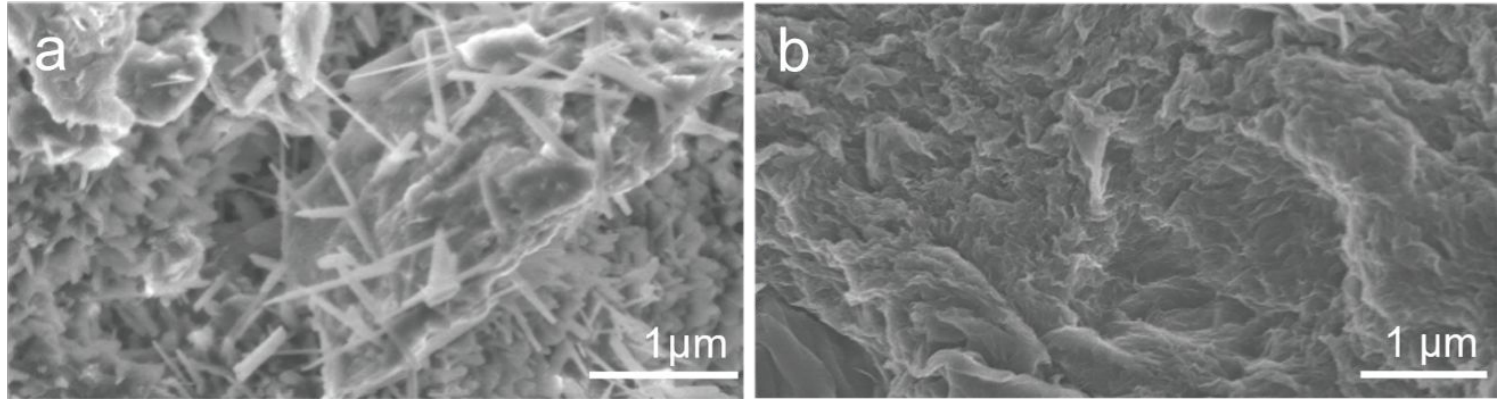

Figure S1. Removal of sodium carbonate from the xerogel by treatment with concentrated sufuric acid. (a) SEM micrograph of xerogel powder after short solvent exchange and ambient drying, showing the presence of sodium carbonate salt. (b) Powders are treated by sulfuric acid, removing sodium carbonate from the porous microstructure.
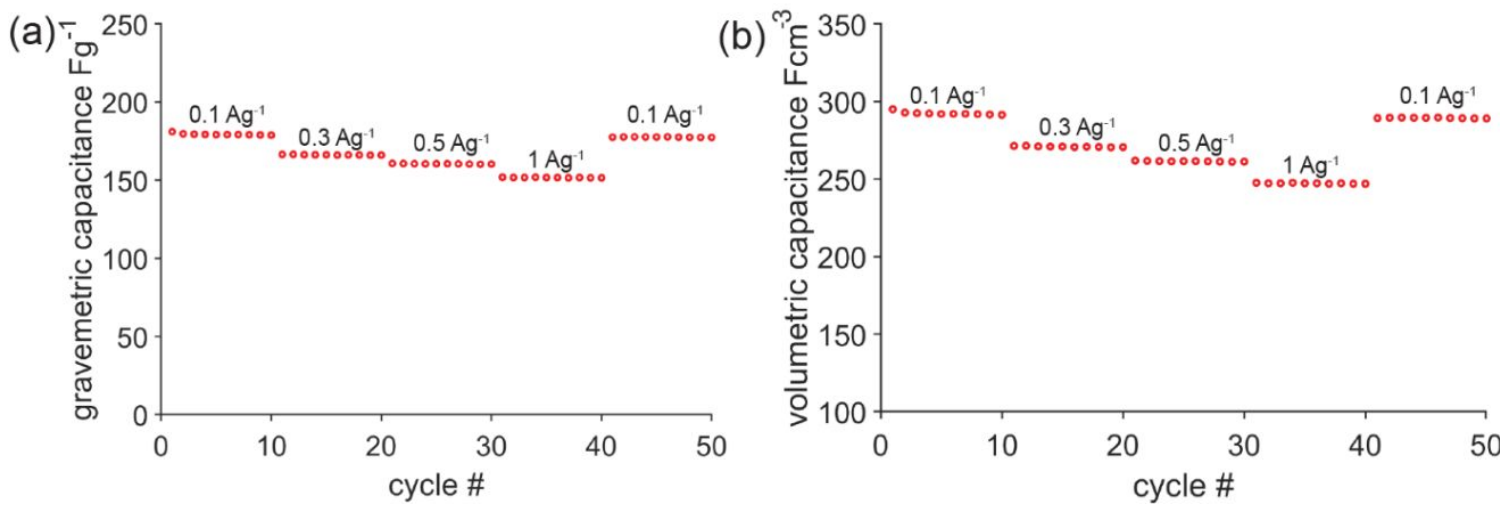

Figure S2. Electrochemical performance of as extruded graphene xerogel in coin cell supercapacitor after 2 week solvent exchange with water. (a) gravemetric performance. (b) volumetric performance. 

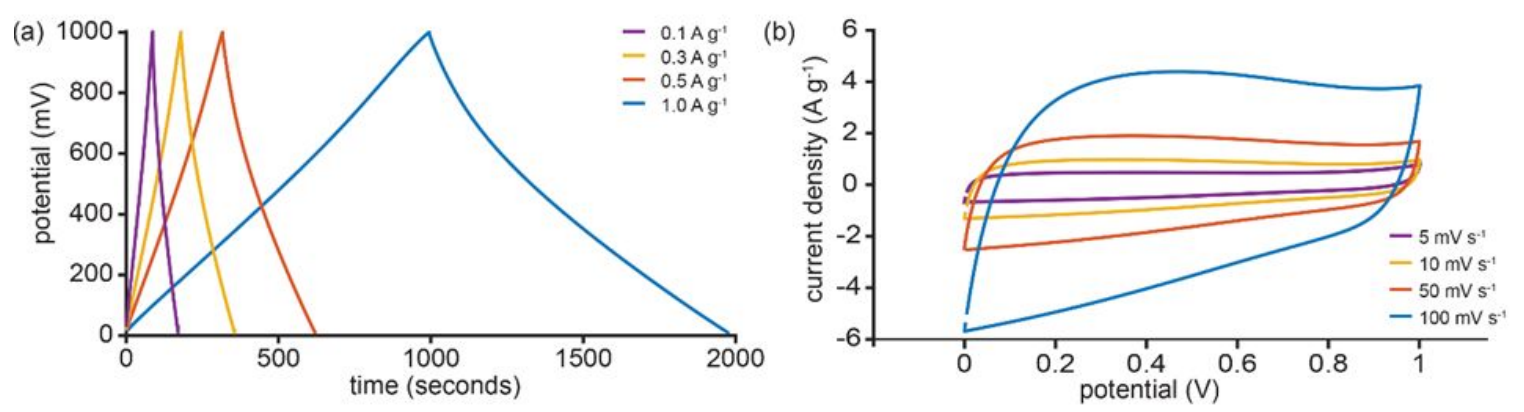

Figure S3. Extended electrochemical characterization. (a) Charge-Discharge cycles of coin cell supercapacitor made from the 350 annealed xerogel powder. (b) Cyclic Voltametry of coin cell supercapacitor showng good capacitive behavior. Electrochemical surface area was estamated using the $5 \mathrm{mVs}^{-1}$ scan rate (closest to equilibrium conditions), resulting in a value of $\sim 274 \mathrm{~m}^{2} \mathrm{~g}^{-1}$.

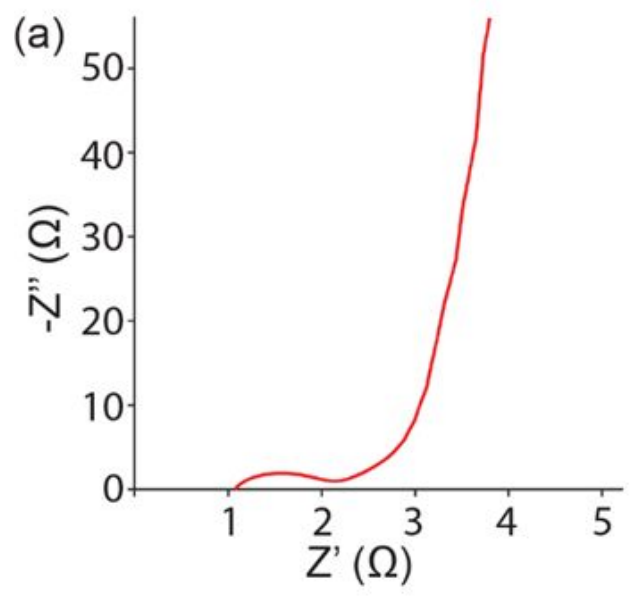

(b)

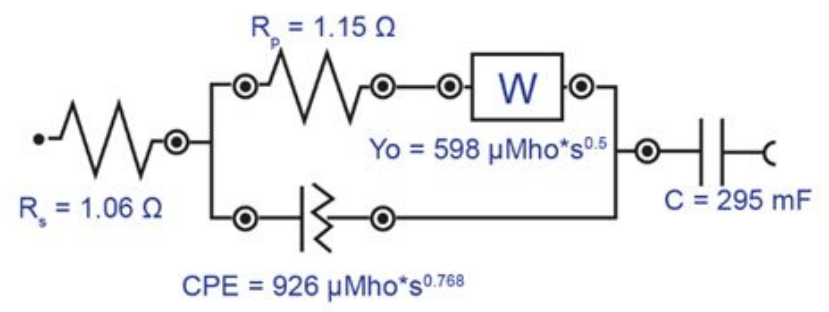

Figure S4. (a) Electrochemical impedance spectrum of a coin cell supercapacitor, showing low internal resistance and good charge transfer kinetics (Warburg resistance $\mathrm{W}$ ), where $\mathrm{R}_{\mathrm{s}}$ is the resistance of electrolyte and $R_{p}$ the resistance of the electrode (b). 

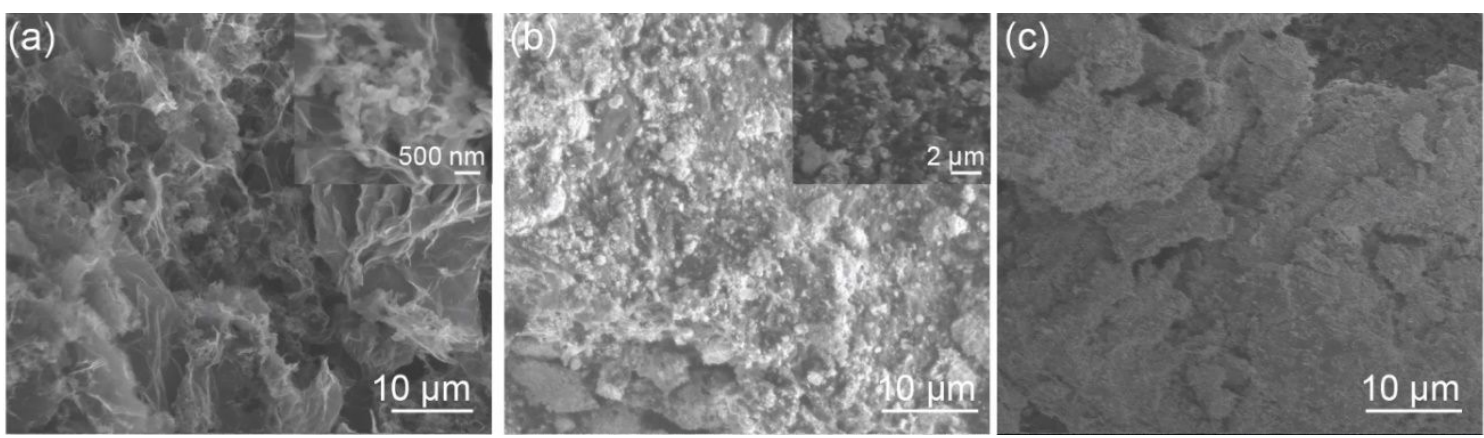

Figure S5. Proof-of-concept for flow synthesis of graphene-based composites, levering GO's surfactant-like property to disperse other materials. (a) SEM micrograph of doped polyaniline nanofibers co-extruded with GO with the inset figure showing a bundle of nanofibers. (b) Nickel metal powder was dispersed into the viscous GO/EG dispersion and coextruded to form the composite. (c) Super P carbon black particles co-extruded with GO.

\begin{tabular}{l|l} 
Sample & Conductivity \\
\hline As extruded xerogel & $\sim 34 \mathrm{~S} \mathrm{~m}^{-1}$ \\
$350^{\circ} \mathrm{C}$ annealed xerogel & $\sim 49 \mathrm{~S} \mathrm{~m}^{-1}$
\end{tabular}

Table S1. Conductivity of as extruded xerogel and annealed xerogel powders by making pellets and using two-probe measurement in a Keithley 2400 source meter. 